\title{
Electromechanical study the wind energy conversion system based DFIG and SCIG generators
}

\author{
Samir Bellarbi \\ Center for Renewable Energy Development CDER, BP. 62 Route de l'Observatoire \\ Bouzareah, 16340, Alger, Algeria
}

Received: January 9, 2021. Revised: June 21, 2021. Accepted: July 5, 2021. Published: July 14, 2021.

\begin{abstract}
Generally speaking, asynchronous generators are used more frequently in medium power in wind energy conversion systems WECS applications. Depending on the power electronics converter used in the specific application, the operation of the asynchronous machine can be controlled in nested speed torque loops, using different torque control algorithms. Because WECS are highly nonlinear systems, but with smooth nonlinearities, a possible optimal control design solution can be the maximum power point tracking MPPT in this paper. This research describes a comparison of the power quality for wind power systems based on two generators: the squirrelcage induction generator (SCIG), the doubly fed induction generator (DFIG). At first, we simulated SCIG and DFIG in MATLAB/Simulink and investigates the impact of this generators on the power system stability for compare the results and to comment on the best option based on the output characteristics of the generator and wind turbine. The technical objective of this research is to choose the most suitable generator adaptive with changing wind speeds and the most energy production
\end{abstract}

Keywords- WECS, SCIG, DFIG, MPPT, Wind turbine, PI controller, Simulation

\section{INTRODUCTION}

Wind energy conversion systems WECS constitute a mainstream power technology that is largely underexploited. Wind technology has made major progression from the prototypes of just 40 years ago. Forth decades of technological progress has resulted in today's wind turbines looking and being much more like power stations, in addition to being modular and rapid to install. From this viewpoint, controlled electrical generators are systems whose inputs are stator and rotor voltages, having as state variables the stator and rotor currents or fluxes. They are composed of an electromagnetic subsystem, which outputs the electromagnetic torque, and the electromechanical subsystem, through which the generator experiences a mechanical interaction. Figure 1 and figure 2 illustrates the modelling principle for the SCIG and DFIG cases $[1,2]$. This leads to many differences in steady-state electrical characteristics, mechanical curves and dynamic responses when connected to the grid. There are published studies related to DFIG speed control methodologies for electric power production in, these studies have proven that the DFIG generator has a higher efficiency and quality energy production in variable wind speeds $[3,4]$, and there are also many studies for SCIG generators, which it's source of reactive power [5]. The DFIG grid connection relies upon the same hardware. Unlike the SCIG, the DFIG is more flexible, being able to operate as a generator (at negative torque) both in sub-synchronous (positive slip) and over-synchronous (negative slip) regimes, and can possible to achieve maximum power points tracking (MPPT) by these types of systems [6]. Comparison between DFIG and SCIG are made in different cases $[5,6]$. The modeling and controlling strategies were described and compared during power system disturbances; this research investigates stability of two different wind generator configurations. This paper also introduced mathematical modeling of these wind generators. After simulations, all results are compared and analyzed. 


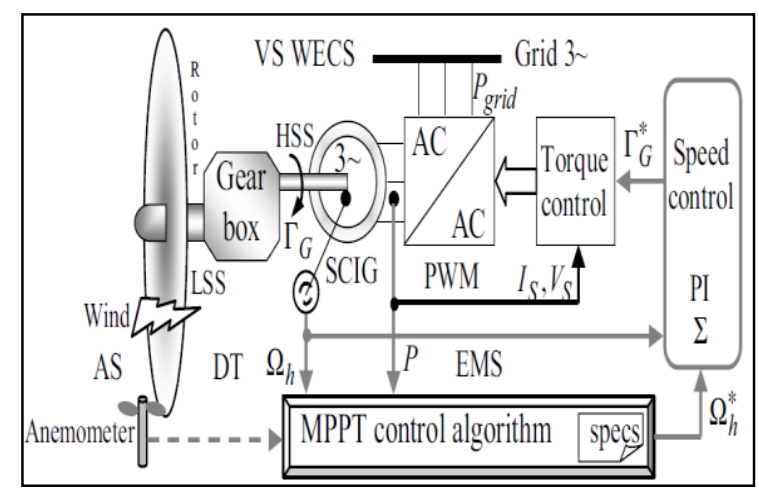

Fig. 1 The MPPT-controlled SCIG-based WECS [7].

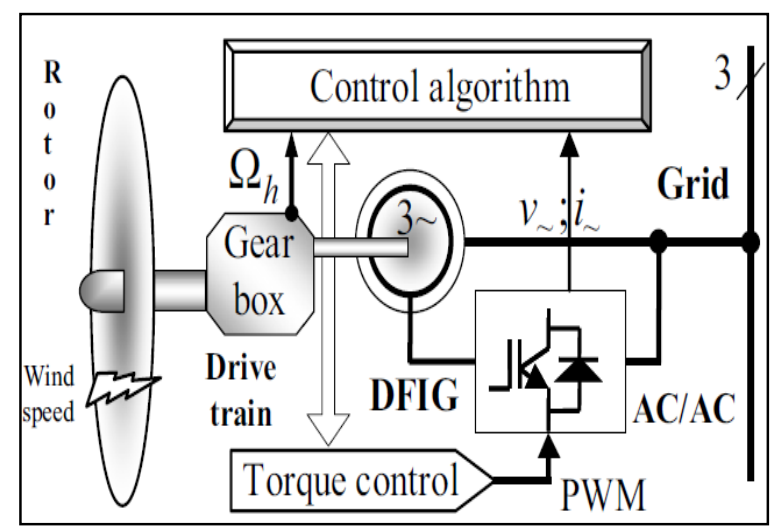

Fig. 2 DFIG-based WECS operating at variable speed by torque control [8].

\section{MODELING}

\section{A. DFIG wind power system}

The electromagnetic torque of doubly-fed induction generator is expressed in $(\mathrm{d}, \mathrm{q})$ as $[9,10$, 11]:

$$
T_{G}=\frac{3}{2} p L_{m}\left(i_{s q} i_{r d}-i_{r q} i_{s d}\right)
$$

With

$P$ : being the pole pairs number,

$L_{m}$ : the stator-rotor mutual inductance,

$i_{s d}, i_{s q}, i_{r d}, i_{r q}$ : are the stator and the rotor current $(d, q)$ components.

Combining the differential equations, we get:

$$
\left|\begin{array}{l}
\frac{d i_{S d}}{d t}=\frac{V_{S d}}{L_{S}}-\frac{R_{S}}{L_{S}} \cdot i_{S d}-\frac{L_{m}}{L_{S}} \cdot \frac{d i_{R d}}{d t}+\omega_{S} \cdot\left(i_{S q}+\frac{L_{m}}{L_{S}} \cdot i_{R q}\right. \\
\frac{d i_{S q}}{d t}=\frac{V_{S q}}{L_{S}}-\frac{R_{S}}{L_{S}} \cdot i_{S q}-\frac{L_{m}}{L_{S}} \cdot \frac{d i_{R q}}{d t}+\omega_{S} \cdot\left(i_{S d}+\frac{L_{m}}{L_{S}} \cdot i_{R d}\right. \\
\frac{d i_{R d}}{d t}=\frac{V_{R d}}{L_{R}}-\frac{R_{R}}{L_{R}} \cdot i_{R d}-\frac{L_{m}}{L_{R}} \cdot \frac{d i_{S d}}{d t}+\left(\omega_{S}-\omega\right) \cdot\left(i_{R q}+\frac{L_{m}}{L_{R}} \cdot i_{S q}\right. \\
\frac{d i_{R q}}{d t}=\frac{V_{R q}}{L_{R}}-\frac{R_{R}}{L_{R}} \cdot i_{R q}-\frac{L_{m}}{L_{R}} \cdot \frac{d i_{S q}}{d t}+\left(\omega_{S}-\omega\right) \cdot\left(i_{R d}+\frac{L_{m}}{L_{R}} \cdot i_{S d}\right.
\end{array}\right|
$$

Where

$\omega$ : is the electrical speed,

$\omega_{S}:$ is the stator field frequency,

$R_{S}, R_{R}$ : stator and rotor resistances,

$L_{S}, L_{R}$ : inductances of stator and rotor;

$V_{S d}, \quad V_{R d}$ : are the stator and rotor voltage components (with $V_{R d}=V_{R q}=0$ );

$\Phi_{R d}, \Phi_{R q}$ : components of the rotor flux.

From the above, we get:

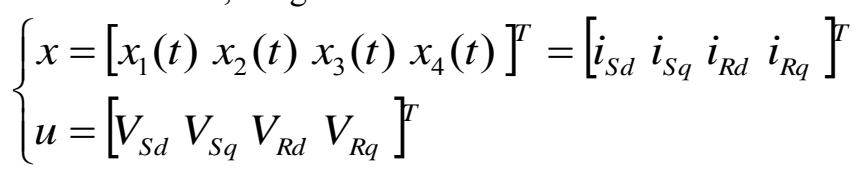

Using the above equations, the DFIG case model becomes as a fourth-order model:

$\left\{\begin{array}{l}\dot{x}=A\left(\Omega_{h}\right) \cdot x+B \cdot u \\ y=T_{G}=\frac{3}{2} p L_{m}\left(x_{1} x_{2}-x_{3} x_{4}\right)\end{array}\right.$

With

$$
\begin{aligned}
& \sigma=1-\frac{L_{m}^{2}}{L_{S} L_{R}} \\
& A\left(\Omega_{h}\right)=\left[\begin{array}{cccc}
-\frac{R_{S}}{\sigma L_{S}} & \omega_{S}+\frac{p \Omega_{h} L_{m}^{2}}{\sigma L_{S} L_{R}} & \frac{L_{m} R_{R}}{\sigma L_{S} L_{R}} & \frac{p L_{m} \Omega_{h}}{\sigma L_{S}} \\
-\left(\omega_{S}+\frac{p \Omega_{h} L_{m}^{2}}{\sigma L_{S} L_{R}}\right)-\frac{R_{S}}{\sigma L_{S}} & \frac{p \Omega_{h} L_{m}}{\sigma L_{S}} & \frac{L_{m} R_{R}}{\sigma L_{S} L_{R}} \\
\frac{R_{S} L_{m}}{\sigma L_{R} L_{S}} & -\frac{p L_{m} \Omega_{h}}{\sigma L_{R}} & -\frac{R_{R}}{\sigma L_{R}} & \omega_{S}-\frac{p \Omega_{h}}{\sigma} \\
\frac{p \Omega_{h} L_{m}}{\sigma L_{R}} & \frac{L_{m} R_{S}}{\sigma L_{R} L_{S}} & \frac{p \Omega_{h}}{\sigma}-\omega_{S} & -\frac{R_{R}}{\sigma L_{R}}
\end{array}\right.
\end{aligned}
$$

$$
B=\left[\begin{array}{cccc}
\frac{1}{\sigma L_{S}} & 0 & \frac{-L_{m}}{\sigma L_{R} L_{S}} & 0 \\
0 & \frac{1}{\sigma L_{S}} & 0 & \frac{-L_{m}}{\sigma L_{S} L_{R}} \\
\frac{-L_{m}}{\sigma L_{S} L_{R}} & 0 & \frac{1}{\sigma L_{R}} & 0 \\
0 & \frac{-L_{m}}{\sigma L_{S} L_{R}} & 0 & \frac{1}{\sigma L_{R}}
\end{array}\right]
$$

Knowing that matrix A depends on the rotational variable speed $\Omega_{h}$, the electromagnetic torque is the output variable (equation 1).

\section{B. SCIG wind power system}

By setting $V_{R d}=V_{R q}=0$ in equation 4 , the state and input vectors for the squirrel-cage induction generator SCIG are as follows $[12,13]$ :

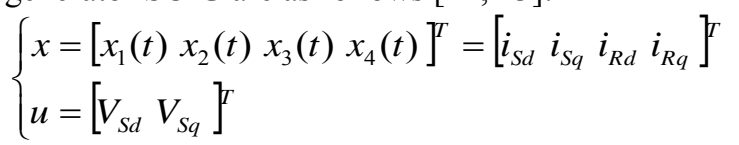

The state model as follows

$\left\{\begin{array}{l}\dot{x}=A\left(\Omega_{h}\right) \cdot x+B_{1} \cdot u \\ y=T_{G}=\frac{3}{2} p L_{m}\left(x_{2} x_{3}-x_{1} x_{4}\right)\end{array}\right.$ 
Where: Matrix $A\left(\Omega_{h}\right)$ is the same as in equation 6 , and:

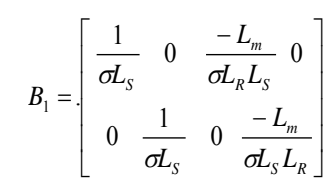

\section{Wind power modeling}

The wind power generated by turbine is given by $[14,15]$ :

$$
P_{w t}=\frac{1}{2} \cdot \rho \cdot \pi R^{2} \cdot V^{3}
$$

\section{Where}

$P_{w t}:$ is wind power captured,

$\rho:$ air density $\left(\mathrm{kg} / \mathrm{m}^{3}\right)$,

$R$ : blade radius (m)

$V$ : wind speed $(\mathrm{m} / \mathrm{s})$.

The resulting mechanical wind power depends on the power coefficient $C_{p}$ through:

$$
P_{m e c}=C_{p} P_{w t}=\frac{1}{2} C_{p} \cdot \rho \cdot \pi R^{2} \cdot V^{3}
$$

\section{Drive train modeling}

From references $[16,17,18]$ :

$$
\begin{aligned}
& 2 J_{T} \frac{d \Omega_{T}}{d t}=-K_{S} \lambda_{T G}+T_{T}-D_{S}\left(\omega_{T}-\omega_{G}\right) \\
& 2 J_{G} \frac{d \Omega_{G}}{d t}=-T_{E}+K_{S} \lambda_{T G}-D_{S}\left(\omega_{T}-\omega_{G}\right) \\
& \frac{d \lambda_{T G}}{d t}=\omega_{0}\left(\omega_{T}-\omega_{G}\right)
\end{aligned}
$$

With

$J_{T}, J_{G}$ : inertia constant (turbine rotor, generator rotor),

$D_{s}, K_{s}$ : damping constant and shaft stiffness,

$\lambda_{T G}$ : electrical twist angle of the shaft,

$\omega_{0}$ : reference angular speed,

$\omega_{r}, \omega_{G}$ are the shaft angular speeds at the ends of the turbine and generator,

$T_{T}, T_{E}$ : mechanical and electrical torque.

\section{E. Controller Design}

The structure of PI controller used is shown in figure 3 , and the principal time constant as follows $[19,20]$ :

$T_{p t}=1 / K_{2}$, the gain $K_{p t}=K_{1} / K_{2}$.

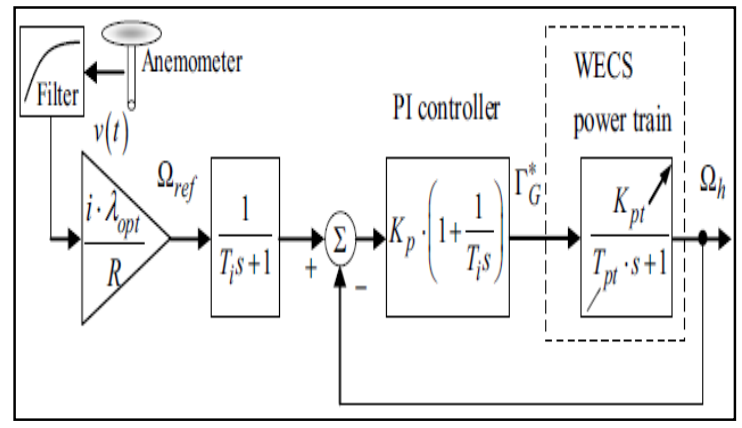

Fig. 3 structure of PI controller.
The controller parameters gives as:

$$
\left\{\begin{array}{l}
T_{i}=\frac{2 \xi}{\omega_{n}}-\frac{1}{\omega_{n}^{2} T_{p t}} \\
K_{p}=\frac{T_{i} T_{p t}}{K_{p t}} \omega_{n}^{2}
\end{array}\right.
$$

Where:

$\omega_{n}$ : natural frequency.

$\xi$ : damping factor.

\section{SiMULATION RESULTS AND DISCUSSION}

Two cases of wind turbine operation were conducted in this simulation: a wind turbine with SCIG (blue curves), a wind turbine with DFIG (red curves), the wind velocity is always fluctuating. To compare the dynamic response of each model, all the wind turbines identical wind with the mean velocity between $5.5 \mathrm{~m} / \mathrm{s}$ to $8 \mathrm{~m} / \mathrm{s}$ represented in figure 4. Figure 5 compares the rotation speed, figures 6 and 7 compares the active power and power coefficient respectively.

Simulations were performed in MATLAB using the nonlinear model. PI controller is adaptive for a wind speed variation. The object of this control is to power compare of the systems of Figure 1 and 2.

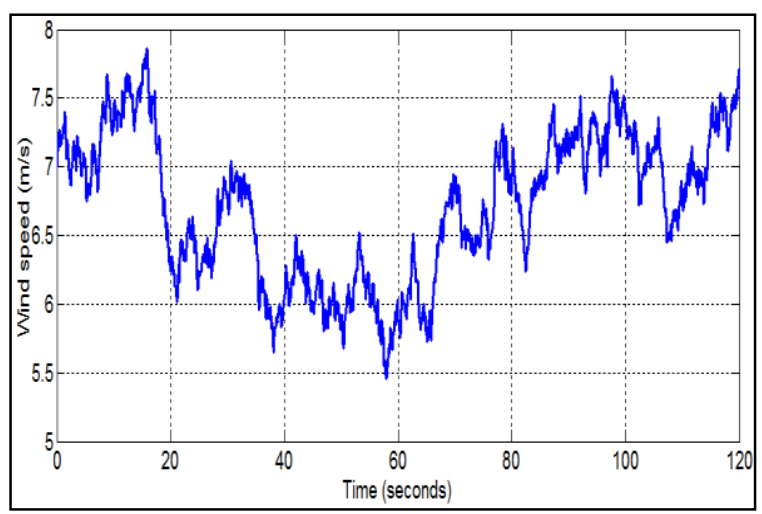

Fig 4. Wind sample.

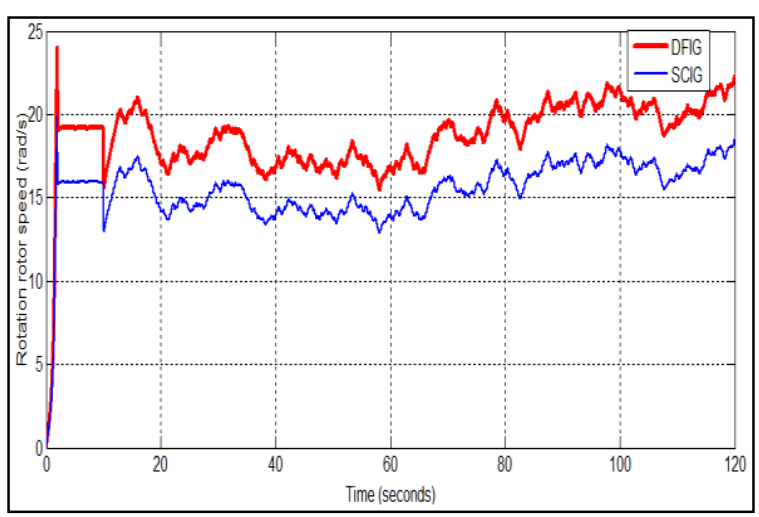

Fig 5. Shaft speed rotation. 


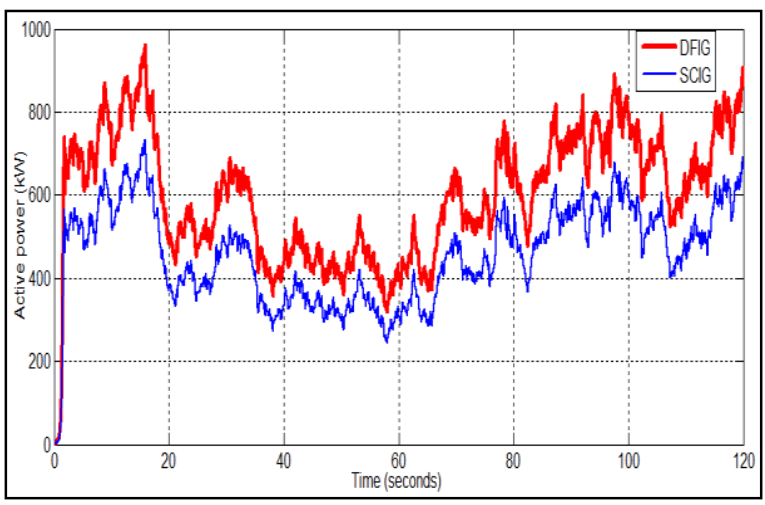

Fig 6. Wind turbine power profile.

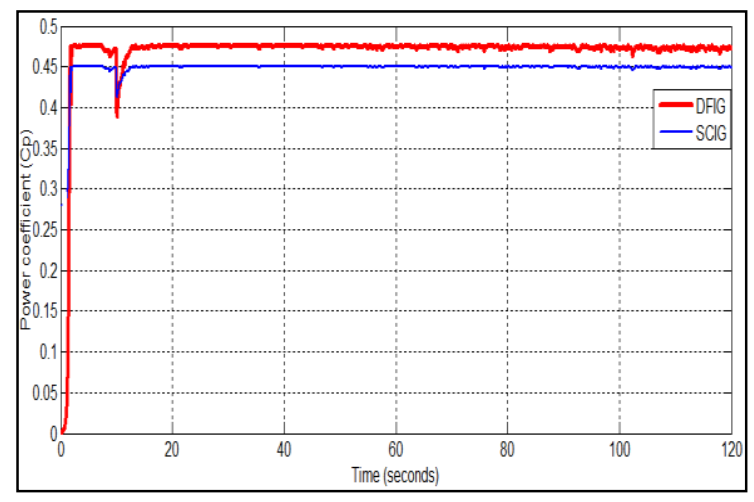

Fig 7. power coefficient profile.

With random variation of wind speed, it has been observed that both the rotation speed and active power fluctuate continuously as illustrated in figure 5 and figure 6. According to figure 6, wind turbine with SCIG shows a power fluctuation later comparing with DFIG.

We see in Figure 7 that the energy efficiency of the MADA better than SCIG.

\section{CONCLUSIONS}

The present study focuses on the doubly fed induction generator and the squirrel-cage induction generator machines, which uses in single-sided grid connection. The numerical modeling is based on a Matlab simulink environment, where the power performances of the SCIG and DFIG are compared in single-sided grid connection systems. In this work, the concept and modeling comparisons are analyzed in order to apply the best proposed schemes to the wind energy conversion system. According to the results, we can conclude that: the active power of squirrel-cage induction generator reaches a maximum value later than the doubly fed induction generator. The rotor speed of the generator in the DFIG system increases with time although the instability of wind velocity.
To conclude, this control structure feeding an induction machine by means of a voltage source inverter allows a very fast control of the wind turbine high-speed shaft. It can also easily be embedded into a speed or power control loop.

\section{RÉFERENCES}

[1] W. Yu, S. Huang, D. Jiang, "A fault monitoring method for wind power generationsystem based on sliding mode observer", Bulletin of the Polish Academy of Sciences Technical Sciences Vol. 69, No. 3, 2020.

[2] M. Davoudi, A. Kasiri Far, "Recurrent Neural Network based MPPT Control of Grid Connected DFIG for Wind Turbine", WSEAS Transactions on Computer Research, Vol. 8, Issue 1, pp. 1-10, 2020.

[3] Y. Zou, E. Elbuluk, Y. Sozer, "Simulation Comparisons and Implementation of Induction Generator Wind Power Systems", IEEE Transactions on Industry Applications, Volume: 49, Issue 3, 2013.

[4] S. Darvishi-Niafenderi, "Differences between SCIG and DFIG Inertia Response", Tech J Engin \& App Sci., 3 (9): 812-818, 2013.

[5] H. Ahuja, R. Virmani, A. Ahuja, "Performance comparison of most prevalent wind energy conversion systems", IEEE Xplore journal DOI: 10.1109/IICPE.2016.8079427.

[6] K. Hsiung Tan, "Squirrel Cage Induction Generator System Using Wavelet Petri Fuzzy Neural Network Control for Wind Power Applications", IEEE Transactions on Power Electronics, Vol. 31, Issue 7, 2016.

[7] B. Majout, D. Abrahmi, Y. Ihedrane, C. El Bakkali, K. Mohammed, B. Bossoufi, "Improvement of Sliding Mode Power Control for WECS based on DFIG-Generator", WSEAS Transactions on Computer Research, Vol. 8, Issue 5, pp. 26-33, 2020.

[8] H. Lallouani, B. Saad, "Performancesof type 2 fuzzy logic control based on direct torque control for double star induction machine", Rev. Roum. Sci. Techn.- Électrotechn. et Énerg. Vol. 65, 1-2, pp. 103-108, Bucarest, 2020.

[9] N. Altin, "The Type-2 Fuzzy Logic ControllerBased Maximum Power Point Tracking Algorithm and the Quadratic Boost Converter for Pv System", Journal of Electronic Materials, vol. 47, p. 4475-4485, 2018.

[10] S. Hassan, B. Abdelmajid, Z. Mourad, S. Aicha, B. Abdenaceur, "PSO-Backstepping Design for Sharing Active and Reactive Power in Grid Connected DFIG based Wind Turbine", WSEAS Transactions on Circuits and Systems, Vol. 20, Issue 4, pp. 33-42, 2021. 
[11] S. Bellarbi, D. Saheb Koussa, "Fuzzy Robust Control of double-fed asynchronous generator with parameter uncertainties", Rev. Roum. Sci. Techn. -Électrotechn. et Énerg., 61, 4, p. 367 371, Bucarest, 2016.

[12] E. Touti, H. Kraim, R. Pusca, " Modeling of an isolated induction generatorconsidering saturation effect ", Bulletin of the Polish Academy of Sciences Technical Sciences Vol. 67, No. 4, 2018.

[13] Y. Ihedrane, C. El Bekkali, B. Bossoufi, M. El Ghamrasni, H. Mahmoudi, "Improved Power Control for an Isolated DFIG based WECS, WSEAS Transactions on Systems", Vol. 18, Issue 32, pp. 253-261, 2019.

[14] S. BELlARBI, D. SAHEB KOUSSA, A. DJOUDI, "Sliding Mode Control for PMSGbased Wind Power System", Journal of Physics: Conf. Series $1081 \quad$ (2018) 012012, doi:10.1088/1742-6596/1081/1/012012.

[15] S. Bellarbi, "Analysis and design of wind energy system based on nonlinear speed controller", Journal of Renewable Energies Vol. 22 Issue 2,p. 295 - 302, 2019.

[16] D. Saheb Koussa, Y. Bouchahma, M. Koussa, S. Bellarbi, A. Boufertella, "Simulation of a wind generator coupled to adiesel generator", International Renewable Energy Congress (IREC), 1-6, 2016.

[17] P. Kumar, M. Kumar, N. Pal, "An efficient control approach of voltage and frequency regulation in an autonomous microgrid", Rev. Roum. Sci. Techn. -Électrotechn. et Énerg., 66, 1, p. 33 -39, Bucarest, 2021.

[18] G. Salloum, "Analytical design of fractional order proportional integral controller for enhanced power control of doubly-fed induction generateur", Rev. Roum. Sci. Techn. Électrotechn. et Énerg., 65, 1-2, p. $109-115$, Bucarest, 2020.

[19] K. Vishnu, R. Nema, A. Ojha, "Boost Converter with Fuzzy Logic, PI Controller and Sliding Mode Control for a Variable Source Input", IEEE Xplore journal 2020 DOI:10.1109/CISPSSE49931.2020.9212297.

[20.] O. Turksoy, S. Ayasun, Y. Hames, "Computation of Robust PI-Based Pitch Controller Parameters for Large Wind Turbines", Canadian Journal of Electrical and Computer Engineering, Vol. 43, Issue 1, 2020.

\section{ANNEX}

Induction generator parameters are:

$P_{n}=1.5 \mathrm{MW}, V=690 \mathrm{~V}$ and $f=50 \mathrm{~Hz}, R_{s}=0,0073 \Omega$, $R_{r}=0,006 \Omega, L_{s}=0,173 \mathrm{H}, L_{r}=0,158 \mathrm{H}, L_{m}=0,158 \mathrm{H}$.

Subscripts

$\omega_{s}, \omega_{r}:$ Stator and rotor angular frequencies,

$\Omega_{g}$ : Mechanical generator speed,

$n_{p}$ : Pole pairs numbers,

$i_{s d}, i_{r d}$ : Current stator and rotor $d$ axis,

$i_{s q}, i_{r q}$ : Current stator and rotor $q$ axis,

$V_{S d}, V_{R d}$ : Voltage stator and rotor $d$ axis,

$V_{S q}, V_{R q}$ : Voltage stator and rotor $q$ axis,

$R_{s}, R_{r}$ : Resistance stator and rotor,

$L_{s}, L_{r}$, Leakage stator and rotor,

$L_{m}$ : Inductances magnetic,

$V_{s}:$ Value of stator voltage,

$\tau_{\mathrm{g}}$ : Constant of time,

$T_{h}:$ Shaft torque,

$n_{b}:$ Speed multiplier,

$D_{r}, D_{g}$ : Rotor and generator constants damping, and

$D_{l s}$ : Low-speed shaft equivalent,

$K_{l s}$ : Torsional stiffness equivalent,

$J_{r}, J_{g}$ : Rotor and generator moments inertia,

$T_{g}, T_{\text {g.ref }}$ : Torque generators,

$\lambda$ : Tip speed ratio (TSR),

$C_{p}$ : Power coefficient,

$\Omega_{r}$ : Turbine rotational speed,

$T_{m}$ : Electromagnetic torque,

$T_{r}$ : Aerodynamic torque.

\section{Creative Commons Attribution License 4.0 (Attribution 4.0 International, CC BY 4.0)}

This article is published under the terms of the Creative Commons Attribution License 4.0 https://creativecommons.org/licenses/by/4.0/deed.en US 